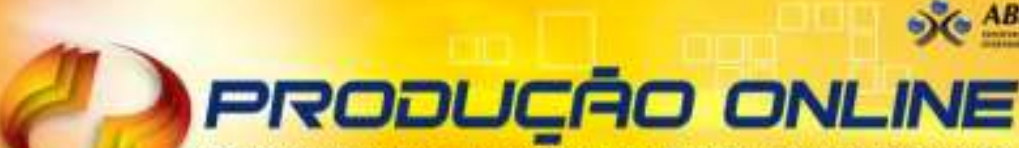 REVISTA CIENTIFICA ELETRONICA DE ENGENHARIA DE PRODUCAO ISSN 1676-1901
}

\section{CIENTOMETRIA DOS SISTEMAS DE PRODUÇÃO LEAN MANUFACTURING E CLEANER PRODUCTION: UM OLHAR NOS PERIÓDICOS DA ABEPRO}

\section{SCIENTOMETRICS OF PRODUCTION SYSTEMS LEAN MANUFACTURING AND CLEANER PRODUCTION: A LOOK AT ABEPRO JOURNALS}

\author{
Nícholas Hoffmann* E-mail: nicholas.hoffmann@hotmail.com \\ Lucas Vinicius Reis* E-mail: lucasviniciusreis@gmail.com \\ Liane Mahlmann Kipper^E-mail: liane@unisc.br \\ *Universidade de Santa Cruz do Sul (UNISC), Santa Cruz do Sul, RS
}

Resumo: A cientometria é o estudo da produção científica por meio de análise quantitativa com o objetivo de verificar a produtividade de publicações referentes às diferentes áreas do conhecimento de diversos países, instituições e pesquisadores. Este estudo analisou a luz da cientometria, a evolução dos sistemas de produção: Manufatura Enxuta e Produção mais Limpa, no campo científico ao longo dos anos, a fim de esquematizar e esclarecer qual é o estado da arte na publicação de artigos desses assuntos no cenário brasileiro. Iniciou pelo levantamento do número de artigos relacionados aos assuntos nos três periódicos que constam no site da ABEPRO e publicações do ENEGEP. As pesquisas buscam a elaboração de uma análise quantitativa sobre a Manufatura Enxuta e Produção mais Limpa, levando em conta os índices dos periódicos como: título, autor, assunto, resumo e texto completo. Dos resultados encontrados destaca-se que as publicações sobre Manufatura Enxuta e Produção mais Limpa estão em crescimento no cenário nacional, porém há uma grande lacuna em relação à utilização dos sistemas de produção em conjunto. É preciso avançar nas pesquisas sobre Manufatura Enxuta e Produção mais Limpa e suas interações para que o conhecimento sobre estes sistemas de produção seja difundido no país e permita um crescimento da produção enxuta e de produção mais limpa e sem desperdícios.

Palavras-chave: Manufatura enxuta. Produção mais limpa. Cientometria

\begin{abstract}
Scientometry is the study of scientific production through quantitative analysis with the objective of verifying the productivity of publications referring to the different areas of knowledge of several countries, institutions and researchers. The aim of this work was to analyze the evolution of the production systems Lean Manufacturing and Cleaner Production in the scientific field over the years, to clarify how the production of articles in the Brazilian scenario occurred. The research started with a survey of the number of articles related to the subjects in the three papers that appear on the ABEPRO website and publications in ENEGEP. Of the results found, it is noted that the publications on Lean and Green are growing in the national scenario, but there is a great gap regarding the use of the production systems together. Further research is needed on Lean Manufacturing and Cleaner Production so that the knowledge of the systems is widespread in the country and allows the growth of lean production and cleaner production without waste.
\end{abstract}

Keywords: Lean Manufacturing. Cleaner Production. Scientometrics.

\section{INTRODUÇÃO}

Os processos industriais são vitais para o progresso e o desenvolvimento da humanidade, porém, eles causam inevitavelmente impactos ao ambiente (DHINGRA 
et al., 2014). A eficiência no uso de materiais está ganhando importância na estratégia operacional das empresas (ALLWOOD et al., 2011). Sistemas de produção como a Manufatura enxuta (Lean manufacturing) e a Produção mais limpa (Cleaner Production) servem para minimizar os impactos ambientais causados pelos processos industriais e diminuir os desperdícios nos diferentes setores da empresa.

O objetivo desta pesquisa é analisar os sistemas de produção Lean Manufacturing e Cleaner Production no campo científico da Engenharia de Produção ao longo dos anos, a fim de esquematizar e esclarecer como evoluiu a produção de artigos desses assuntos nos principais periódicos brasileiros. Assim, a originalidade deste artigo está na busca de correlações entre dois sistemas de produção atuais e necessários ao desenvolvimento sustentável das organizações. A originalidade também se revela no uso da cientometria enquanto caminho para encontrar estas correlações.

A abordagem metodológica utilizada foi a cientometria, conhecida como uma pesquisa quantitativa da produção científica, que segundo Spinak (1998), iniciou na década de 1960 pela Organização das Nações Unidas para a Educação, a Ciência e a Cultura (UNESCO) e a Organização para a Cooperação e Desenvolvimento Econômico (OCDE). Estas duas organizações internacionais observaram a necessidade de metodologias para avaliar e comparar em nível internacional as atividades científicas e tecnológicas. As metodologias desenvolvidas e aceitas internacionalmente estão descritas nos Manuais de Oslo (1992), de Canberra (1995) e de Frascati (2002), e estes manuais são as referências clássicas para medir os insumos e os resultados econômicos, bem como os resultados tecnológicos advindos da pesquisa e desenvolvimento tecnológico (SPINAK, 1998). A cientometria será mais aprofundada no capítulo da metodologia.

Com o intuito de verificar a evolução da produção literária no Brasil, os autores focaram em publicações brasileiras. Então foram escolhidos os periódicos que constam no site da ABEPRO e ainda os trabalhos publicados no ENEGEP.

Sobre a ABEPRO, Associação Brasileira de Engenharia de Produção, é uma instituição de Engenharia de Produção representativa de docentes, discentes e profissionais que atua há mais de 20 anos com as funções de esclarecer a atuação do Engenheiro de Produção quanto à sociedade e ao mercado de trabalho. Também atua como interlocutor com as instituições governamentais que estão envolvidas na 
organização e avaliação de cursos (MEC e INEP) e de fomento como CAPES, CNPq, FINEP e órgãos de apoio às pesquisas estaduais, bem como com organizações privadas, em conjunto com CREA, CONFEA, SBPC, ABENGE, e outras não governamentais envolvidas com pesquisa, ensino e extensão da Engenharia (ABEPRO, 2016).

No seu site, a ABEPRO indica 3 periódicos científicos produzidos por ela e apoiados pelos seus editores, nas quais as pesquisas publicadas englobam muitos temas de interesse da Engenharia de Produção. Os periódicos são as seguintes: Produção Online, que é o primeiro periódico científico, em mídia digital da área de Engenharia de Produção (BONFÁ e CASTRO, 2004), Production (Produção), que tem como objetivo fomentar a geração e a disseminação de conhecimento em Engenharia de Produção publicando artigos inéditos que representem uma contribuição efetiva, tanto sob a forma de resultado de pesquisas empíricas como de desenvolvimento de quadro teórico/conceitual, e BJO\&PM (Brazilian Journal of Operations \& Production). O periódico BJO\&PM publica artigos de vanguarda relacionados à Pesquisa Aplicada em Gestão, cobrindo todos os aspectos de operação e produção para os interessados na gestão, quer na Acadêmica ou em setores industriais. O periódico está associado à ABEPRO. Apenas artigos em Inglês são considerados para apresentação e publicação nestes dois últimos periódicos.

O ENEGEP, Encontro Nacional de Engenharia de Produção, é o maior evento nacional da área de Engenharia de Produção organizado pela ABEPRO - Associação Brasileira de Engenharia de Produção e já está na $37^{a}$ edição. Reúne a comunidade acadêmica, pesquisadores, professores e estudantes, empresários, consultores, engenheiros, administradores e demais profissionais atuantes na Engenharia de Produção. Constitui-se em um dos principais divulgadores da produção técnica e científica da área e se consolidou como fórum de discussão de questões pertinentes à Engenharia de Produção no âmbito nacional (ENEGEP, 2017).

A seguir, conceitos sobre Manufatura enxuta e Produção mais limpa são apresentados com o intuito de entender melhor seus conceitos, suas práticas e ferramentas, e as possíveis formas de se obter uma melhor integração dos mesmos. 


\section{MANUFATURA ENXUTA (LEAN MANUFACTURING)}

A manufatura enxuta é uma filosofia que ajuda empresas a identificar e eliminar desperdícios através de constantes melhorias, controladas por ferramentas e práticas Lean (DOMINGO e AGUADO, 2015; GALEAZZO et al., 2014). São identificados sete desperdícios com o sistema enxuto de produção: superprodução, tempo de espera, transporte, defeitos, processos impróprios, estoque desnecessário e movimentos desnecessários. O objetivo na eliminação desses desperdícios é aumentar a eficiência, reduzir custos, melhorar o tempo de resposta do cliente e contribuir para melhorar a qualidade, aumentar lucros e melhorar a imagem frente ao público (VERRIER et al., 2014).

Como base no Lean, aparecem duas ferramentas, Just in Time e Kanban. No entanto, o sucesso da Toyota com a Lean Manufacturing advém da construção de algo que reúne todos os seus princípios, métodos e técnicas e da aplicação concatenada deste conjunto, não somente de algumas técnicas em particular (GHINATO, 1995).

O objetivo principal do Just in time é não ter estoque, não acumular os produtos, com cada processo suprido com itens em quantidades certas, no tempo e lugar certo. $E$ isso deve ser aplicado a toda a cadeia de suprimentos da empresa (HUTCHINS, 1999). O Kanban é usado junto ao Just in Time para controlar o uso de itens necessários em cada processo, evitando que haja estoque (SUGIMORI, 1977).

Há outras ferramentas utilizadas, como o Value Stream Map (VSM), usadas para encontrar operações ineficientes em um processo através de mapas de fluxo de valor. O Total Quality Management (TQM) melhora e mantém a qualidade de produtos e processos para atender ou superar as expectativas dos consumidores (FURLAN et al., 2011). O FIFO, first in, first out, propõe que os primeiros pedidos ou materiais serão atendidos e usados primeiro, e os últimos por últimos. (ROTHER e SHOOK, 2003).

Para envolver a todos e ter pessoas desenvolvendo os seus trabalhos na mesma direção, é importante entender o que fazer, como fazer e para que uma determinada atividade deva ser feita. Estes fundamentos são o foco para o desenvolvimento de ferramentas e técnicas enxutas (HÖCKERDAL, 2012). 


\section{PRODUÇÃO MAIS LIMPA (CLEANER PRODUCTION)}

A definição de Produção mais Limpa foi desenvolvida pela UNEP em Paris, em 1989 (GLAVIC e LUKMAN, 2007), e busca alcançar melhorias ambientais no processo e desenvolvimento de produtos, bem como maior sustentabilidade ambiental (SEVERO et al., 2015). Ela também está associada à redução dos impactos ambientais ao longo da vida de um produto (DUNN e BUSH, 2001).

A Produção mais Limpa propõe tanto mudanças tecnológicas quanto mudanças no gerenciamento dos processos produtivos. Para isto, deve-se ter uma visão do sistema produtivo e das atividades, para a realização de um diagnóstico. Após, efetua análises e indaga as causas e os efeitos das ações (DUMKE e CALÁBRIA, 2007). Assim, as tecnologias limpas aumentam a produtividade, resultado da economia de custos e racionalização dos resultados nos processos produtivos (GETZNER, 2002).

Em 1992, a Newsletter of Cleaner Production (periódico da UNEP sobre a Produção mais Limpa) publicou quatro asserções que procuram explicar o significado de Produção mais Limpa (BAAS, 1995):

- Produção mais Limpa significa a aplicação contínua de uma estratégia ambiental integrada e preventiva para processos e produtos, a fim de se reduzirem os riscos para as pessoas e o meio ambiente;

- As técnicas de Produção mais Limpa incluem a conservação de matériasprimas e energia, a eliminação de material tóxico nos processos e a redução da quantidade e toxicidade de todas as emissões e resíduos;

- A estratégia de Produção mais Limpa para produtos enfoca a redução dos impactos ambientais ao longo de todo o ciclo de vida do produto (desde a extração da matéria-prima até o definitivo descarte do produto);

- A Produção mais Limpa é obtida pela aplicação de perícia, de melhoria tecnológica e mudanças de atitude (BAAS, 1995).

Para SICSÚ e SILVA FILHO (2003), a Produção mais Limpa, referente à Gestão Ambiental, é uma ferramenta que possibilita o funcionamento da empresa de modo social e ambientalmente responsável, exercendo influência também em melhorias econômicas e tecnológicas, aplicando uma abordagem preventiva em relação à Gestão Ambiental. No quadro 1 apresenta-se uma comparação entre a Manufatura Enxuta e a Produção mais Limpa, realçando os principais conceitos e suas práticas e ferramentas. 
Quadro 1 - Conceitos e práticas dos sistemas de produção Lean Manufacturing e Cleaner Production

\begin{tabular}{|c|c|c|}
\hline $\begin{array}{c}\text { SISTEMAS DE } \\
\text { PRODUÇÃO }\end{array}$ & CONCEITOS & PRÁTICAS/FERRAMENTAS \\
\hline Manufatura Enxuta & $\begin{array}{c}\text { A Manufatura Enxuta é uma } \\
\text { filosofia que ajuda empresas } \\
\text { a identificar e eliminar } \\
\text { desperdícios através de } \\
\text { constantes melhorias, } \\
\text { controladas por ferramentas } \\
\text { e práticas Lean. }\end{array}$ & $\begin{array}{c}\text { Just in Time } \\
\text { Kanban } \\
\text { Value Stream Map } \\
\text { Total Quality Management } \\
\text { First In, First Out }\end{array}$ \\
\hline Produção mais Limpa & $\begin{array}{c}\text { A Produção mais Limpa } \\
\text { busca alcançar melhorias } \\
\text { ambientais no processo e } \\
\text { desenvolvimento de } \\
\text { produtos, bem como maior } \\
\text { sustentabilidade ambiental. }\end{array}$ & $\begin{array}{c}\text { Melhorar uso de matéria prima } \\
\text { e energia }\end{array}$ \\
$\begin{array}{c}\text { Tecnologias Limpas } \\
\text { Diminuir a emissão de } \\
\text { poluentes }\end{array}$ \\
\hline
\end{tabular}

Fonte: Autores (2016)

\section{METODOLOGIA}

Como metodologia, foi escolhida a cientometria, a qual estuda a produção científica por meio de análise quantitativa e tem como objetivo o de verificar a produtividade de publicações referentes às diferentes áreas do conhecimento de diversos países, instituições e pesquisadores, partindo da premissa de que as publicações científicas são um demonstrativo essencial da presença e qualidade das atividades científicas (Bittencourt e Paula, 2012). Do ponto de vista cognitivo, um novo conhecimento somente adquire o seu valor quando ele é difundido dentro da comunidade, pois, somente assim poderá contribuir para o avanço científico (SILVA e BIANCHI, 2001).

O estudo foi iniciado com o levantamento do número de artigos relacionados aos assuntos nos periódicos que constam no site da $A B E P R O$, denominados Periódicos ABEPRO, e os artigos publicados no ENEGEP. As pesquisas buscaram a elaboração de uma análise quantitativa sobre os assuntos Lean Manufacturing e Cleaner Production.

Os termos adotados para a busca nos periódicos da ABEPRO e no ENEGEP foram: "Cleaner Production" (Produção mais Limpa), "Lean Manufacturing", "Lean" and "Green", "Lean" and "cleaner Production", "Green Management", "Green" e "Lean". As pesquisas levaram em conta a periodicidade, o número médio de artigos por edição e 
os índices dos periódicos, como título, autor, assunto, resumo e texto completo abrangendo todas as publicações encontradas, sem restrição quanto ao ano de publicação.

Os periódicos analisados foram: Production (1ำ edição-1990), Produção Online (1 ${ }^{\text {a }}$ edição-2001) e BJO\&PM (1 ${ }^{\text {a }}$ edição-2003).

A periodicidade da Production e Produção Online é trimestral e publicam em média 15 artigos por edição. Já a BJO\&PM teve periodicidade semestral até 2015 e, em 2016, é trimestral, publicando, em média, também, 15 artigos por edição. 0 periódico Production apresenta artigos a partir de 2002 de forma online; então a análise comparativa foi feita com artigos de 2002 a 2016 em todos os periódicos. As pesquisas na Production foram feitas através da base de dados Scielo, pois não foram encontrados resultados diretamente pelo site do periódico.

A periodicidade do ENEGEP é anual e os artigos se encontram de forma online no site da ABEPRO. A pesquisa abordou os últimos dez anos, de 2007 a 2016, pois não foram encontrados artigos anteriores a esta data.

Os artigos encontrados no cruzamento dos termos "Lean" e "Cleaner Production" foram analisados a partir do título, resumo e palavras-chave para uma rápida filtragem dos artigos que não apresentavam a integração dos sistemas. Após essa filtragem, os artigos restantes foram completamente lidos e analisados, e uma síntese foi elaborada apresentando os objetivos, metodologias utilizadas, resultados, conclusões e possíveis lacunas do conhecimento. Essa síntese é apresentada nos resultados e discussões a seguir.

\section{RESULTADOS E DISCUSSÕES}

Dos principais resultados encontrados, destacam-se 784 artigos obtidos no total, distribuídos nos periódicos analisados e no ENEGEP. Dos artigos relacionados com os termos de busca, a maioria foi publicada no ENEGEP, resultando em 531 artigos. Na Produção Online, 209 artigos foram publicados. Na Production, foram encontrados 31 artigos e na BJO\&PM, 13 publicações no período pesquisado. A pesquisa foi realizada no mês de agosto de 2016.

O termo único de busca mais encontrado em todos os periódicos foi o "lean" com 370 publicações relacionadas. Quando foi realizado o cruzamento dos termos de 
busca "lean" e "cleaner production", apenas oito artigos foram encontrados, cinco no periódico Produção Online e três no ENEGEP. Este resultado revela que a relação entre os dois termos de busca, "lean" e "cleaner production", é um campo de estudo pouco explorado. Outra informação percebida é que não foram encontrados artigos utilizando o termo de busca "Green Management" nos periódicos analisados, apenas publicados no ENEGEP, o que reforça a nossa proposição de avanço em novas pesquisas. Na Tabela 1 é apresentado o número de artigos encontrados para cada termo de pesquisa utilizado, distribuídos entre os três periódicos e o ENEGEP.

Tabela 1 - Quantidade de artigos encontrados nos periódicos e no ENEGEP referentes às palavraschave

\begin{tabular}{lcccc}
\hline PALAVRAS-CHAVE & $\begin{array}{c}\text { PRODUÇÃO } \\
\text { ONLINE } \\
\text { Quant. }\end{array}$ & $\begin{array}{c}\text { REVISTAS } \\
\text { BJO\&PM } \\
\text { Quant. }\end{array}$ & $\begin{array}{c}\text { PRODUCTION } \\
\text { Quant. }\end{array}$ & $\begin{array}{c}\text { ENEGEP } \\
\text { Quant. }\end{array}$ \\
\hline "cleaner production" & 37 & 0 & 5 & 91 \\
"lean manufacturing" & 30 & 2 & 2 & 96 \\
"lean" e "green" & 17 & 0 & 0 & 5 \\
"lean" e "cleaner production" & 5 & 0 & 0 & 3 \\
"green management" & 0 & 0 & 0 & 22 \\
"Green" & 41 & 1 & 9 & 48 \\
"Lean" & 79 & 10 & 15 & 266 \\
Total & 209 & 13 & 31 & 531 \\
\hline
\end{tabular}

Fonte: Autores (2016)

O gráfico apresentado na Figura 1 informa o número de artigos encontrados em cada periódico e no ENEGEP, relacionado com os termos de busca utilizados na cientometria. 




Fonte: Autores (2016)

A Figura 1 evidencia os resultados da Tabela 1, no qual o termo de busca Lean obteve o maior número de resultados, seguido pelos termos Cleaner Production e Lean Manufacturing. A maioria dos artigos publicados foi encontrada nos Anais do ENEGEP. Entre os periódicos, destaca-se a Produção Online com o maior número de publicações.

A Figura 2 apresenta a evolução das publicações encontradas de acordo com a Tabela 2, relacionando o número de artigos encontrados através dos anos, começando em 2002 até 2016, em cada um dos três periódicos da ABEPRO e publicações no ENEGEP, de 2007 até 2016. 
Tabela 2 - Artigos encontradas nos periódicos e no ENEGEP por ano de publicação

PRODUÇÃOO ENEGEP

\begin{tabular}{ccccc} 
ANOS & ONLINE & BJO\&PM & PRODUCTION & \\
\hline 2016 & 23 & 2 & 3 & 92 \\
2015 & 27 & 0 & 10 & 74 \\
2014 & 39 & 0 & 5 & 63 \\
2013 & 29 & 0 & 2 & 32 \\
2012 & 26 & 4 & 1 & 59 \\
2011 & 12 & 4 & 1 & 62 \\
2010 & 19 & 0 & 1 & 57 \\
2009 & 10 & 2 & 1 & 28 \\
2008 & 7 & 1 & 2 & 47 \\
2007 & 3 & 0 & 4 & 17 \\
2006 & 2 & 0 & 0 & 0 \\
2005 & 4 & 0 & 0 & 0 \\
2004 & 2 & 0 & 0 & 0 \\
2003 & 5 & 0 & 1 & 0 \\
2002 & 1 & 0 & 0 & 0 \\
Total & 209 & 13 & 31 & 531
\end{tabular}

Fonte: Autores (2016)

Figura 2 - Evolução de artigos publicados no decorrer dos anos/periódicos

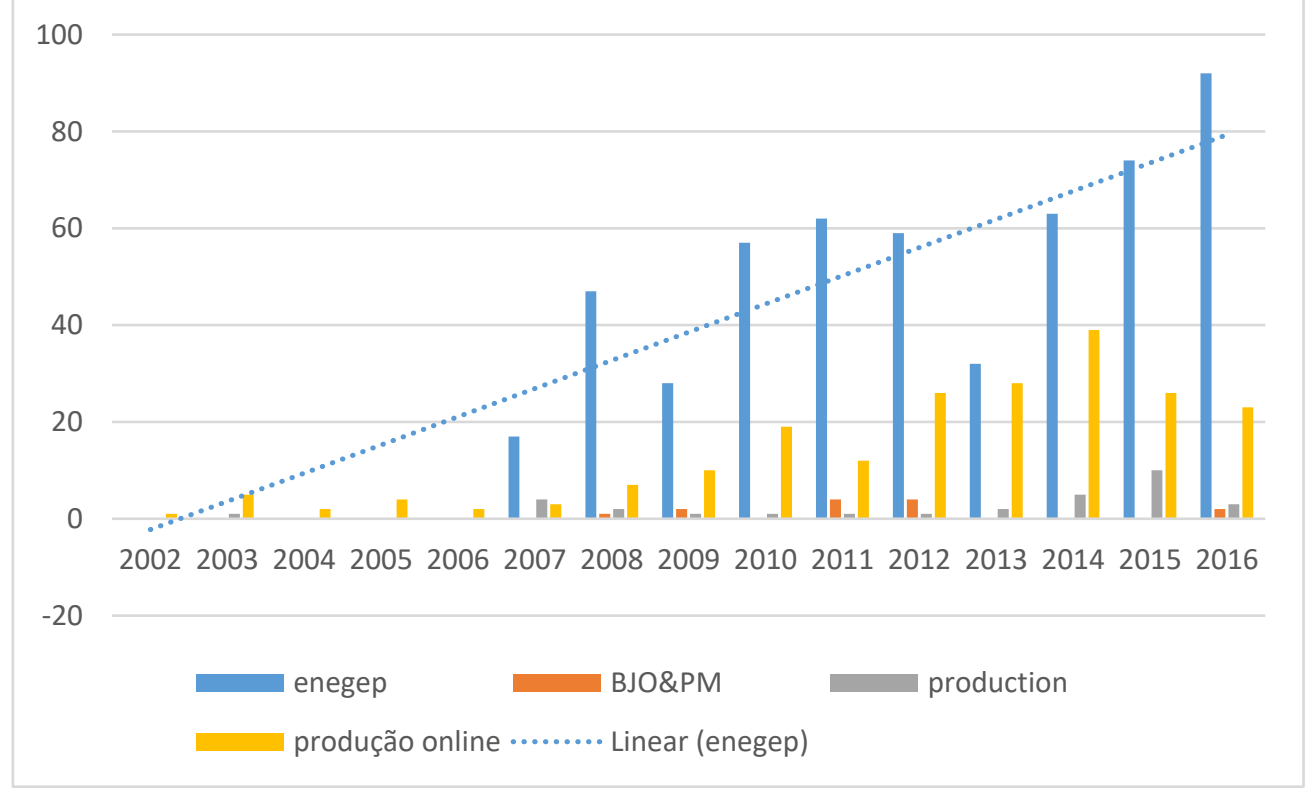

Fonte: Autores (2016)

Revista Produção Online. Florianópolis, SC, v. 18, n. 1, p. 329-349, 2018. 
Na Figura 2, é apresentada uma linha de tendência a partir dos resultados obtidos na avaliação dos artigos publicados nos anais do ENEGEP. Os resultados mostram um crescente a partir de 2002. Em 2015 não houve crescimento do número de publicações no periódico Produção Online, porém no periódico Production, de 2014 para 2015, o número de artigos dobrou.

Com a cientometria foram encontrados oito artigos com os termos de busca "Lean" "e "Cleaner Production", dos quais foram lidos o título, resumo e palavras-chave e, destes oito, apenas três apresentaram a integração dos sistemas de produção.

A seguir é feita uma análise qualitativa dos 3 artigos encontrados na pesquisa com os termos "Lean"e "Cleaner Production", através da leitura dos textos e discussão do conteúdo de cada artigo.

\subsection{Trabalhos relacionados}

\subsubsection{Cleaner Production: a growing movement in Brazilian companies (Vendrametto et al., 2010)}

O estudo busca melhorar o uso de embalagens de madeira, papelão e plástico, usando os métodos Lean e Cleaner Production, em uma grande fábrica de veículos e uma pequena indústria de suprimentos médicos.

O artigo faz uma revisão de conceitos e apresenta três estudos de caso, em que se promove mudança na forma de entrega de produtos, eliminando ou reusando volumosas quantidades de embalagens de papelão, plástico e madeira. Foi utilizada a ferramenta de avaliação de material, desenvolvida por Wuppertal Institute, na Alemanha, para avaliar os ganhos ambientais associados com extração de recursos naturais do meio ambiente.

Os resultados mostraram que as empresas obtiveram ganhos financeiros, de espaço e de produtividade, diminuindo o uso de papel, madeira, plástico e papelão.

Há muito a ser feito para prevenir a degradação do ecossistema e reconhecer isso já é um passo importante dentro do contexto econômico atual. Tanto as grandes empresas quanto as pequenas podem incrementar programas de Cleaner Production, sem precisarem grandes investimentos econômicos. 
O fato importante que o artigo revela é a existência de um movimento ainda difuso, mas crescente e incremental entre as empresas, para reduzir ou eliminar produtos e atividades que não agregam valor, agridem o ambiente e desgastam as imagens das empresas frente ao mercado.

\subsubsection{Estudo da interação entre Lean Manufacturing e Green Manufacturing em uma indústria de reforma e recapagem de pneus (Silva Junior J. A. et al., 2014)}

O trabalho analisa o grau de interação entre Lean Manufacturing e Green Manufacturing em uma pequena empresa de venda, reforma e recapagem de pneus e busca identificar os principais desperdícios.

Foi utilizado o estudo de caso como metodologia. Houve uma revisão da literatura para auxílio ao estudo de caso e foram feitas visitas técnicas na empresa para acompanhar o processo produtivo. Houve ainda uma entrevista com funcionários para maiores esclarecimentos.

Houve a integração de Lean e Green no processo de vulcanização, no qual foi realizada uma melhoria para reutilizar o vapor do processo, o que reduziu o tempo necessário para aquecer a água e a diminuição da energia necessária para o processo.

A integração de Lean e Green apresentou bons resultados para a empresa, com redução de custos e diminuição dos impactos ambientais.

\subsubsection{Minimização do passivo ambiental de resíduos líquidos de poliuretanos em indústria de laminados sintéticos através da aplicação sinérgica de ferramentas da Produção mais Limpa e Lean Manufacturing (Kauer R., 2015)}

O artigo apresenta a busca pela minimização do passivo ambiental de resíduos em uma indústria de laminados sintéticos com ferramentas da Produção mais Limpa e de Manufatura Enxuta.

Foram abordados os processos envolvidos na produção de laminados, os quais produzem o poliuretano e há uma explanação sobre a Produção mais Limpa e a 
Manufatura Enxuta, apresentando algumas ferramentas. Foi elaborado um Plano de Ação, a fim de diminuir a geração de resíduos, com o auxílio da ferramenta 5W2H.

Com o Plano de Ação, observou-se uma redução de resíduos durante três meses na produção de poliuretano. Com a utilização de algumas ferramentas como o $5 \mathrm{~W} 2 \mathrm{H}$, mesmo sendo em um curto período, foram obtidos resultados expressivos quanto à diminuição de resíduos de poliuretano. É proposto um novo estudo com ações voltadas ao planejamento e controle de produção.

Dos três artigos que apresentam correlação entre "Lean" e "Cleaner Production", dois trabalhos foram realizados por pesquisadores de universidades do Estado de São Paulo e um artigo tem origem em uma universidade do Rio Grande do Sul. No quadro 2 encontra-se uma síntese comparativa dos artigos revisados.

Quadro 2 - Síntese dos resultados, conclusões e possíveis lacunas do conhecimento apresentados nos artigos

\begin{tabular}{|c|c|c|c|}
\hline AUTORES & RESULTADOS & CONCLUSÃO & $\begin{array}{c}\text { LACUNAS DO } \\
\text { CONHECIMENTO }\end{array}$ \\
\hline $\begin{array}{l}\text { Vendrametto, } \\
\text { O., et al. (2010) }\end{array}$ & $\begin{array}{l}\text { Os resultados mostraram que } \\
\text { as empresas obtiveram } \\
\text { ganhos financeiros, de espaço } \\
\text { e de produtividade, } \\
\text { diminuindo o uso de papel, } \\
\text { madeira, plástico e papelão. }\end{array}$ & $\begin{array}{l}\text { Há muito a ser feito para } \\
\text { prevenir a degradação do } \\
\text { ecossistema e reconhecer } \\
\text { isso já é um passo } \\
\text { importante dentro do } \\
\text { contexto econômico atual. } \\
\text { Tanto as grandes } \\
\text { empresas quanto as } \\
\text { pequenas podem } \\
\text { incrementar programas de } \\
\text { Clean Production, sem } \\
\text { precisarem grandes } \\
\text { investimentos } \\
\text { econômicos. }\end{array}$ & $\begin{array}{c}\text { O artigo revela a } \\
\text { existência de um } \\
\text { movimento ainda } \\
\text { difuso, mas crescente e } \\
\text { incremental entre as } \\
\text { empresas, para reduzir } \\
\text { ou eliminar produtos e } \\
\text { atividades que não } \\
\text { agregam valores, } \\
\text { agridem o ambiente e } \\
\text { desgastam as imagens } \\
\text { das empresas frente ao } \\
\text { mercado. }\end{array}$ \\
\hline $\begin{array}{l}\text { Junior J. A. S. } \\
\text { et al. (2014) }\end{array}$ & $\begin{array}{l}\text { Houve a integração de Lean e } \\
\text { Green no processo de } \\
\text { vulcanização, no qual foi } \\
\text { realizada uma melhoria para } \\
\text { reutilizar o vapor do processo, } \\
\text { o que reduziu o tempo } \\
\text { necessário para aquecer a } \\
\text { água e a diminuição da } \\
\text { energia necessária para o } \\
\text { processo. }\end{array}$ & $\begin{array}{l}\text { A integração do Lean e } \\
\text { Green apresentou bons } \\
\text { resultados para a } \\
\text { empresa, com redução de } \\
\text { custos e diminuição dos } \\
\text { impactos ambientais. }\end{array}$ & - \\
\hline Kauer R. (2015) & $\begin{array}{l}\text { Com o Plano de Ação, } \\
\text { observou-se uma redução de } \\
\text { resíduos durante três meses } \\
\text { na produção de poliuretano. }\end{array}$ & $\begin{array}{l}\text { Com a utilização de } \\
\text { alguns conceitos e } \\
\text { ferramentas Lean e } \\
\text { Produção mais Limpa, } \\
\text { mesmo sendo em um } \\
\text { curto período, foram } \\
\text { obtidos resultados } \\
\text { expressivos quanto à } \\
\text { diminuição de resíduos de } \\
\text { poliuretano. }\end{array}$ & $\begin{array}{l}\text { Propõe-se um novo } \\
\text { estudo com ações } \\
\text { voltadas ao } \\
\text { planejamento e controle } \\
\text { de produção. }\end{array}$ \\
\hline
\end{tabular}

Fonte: Autores (2016) 
Todos os autores comentam sobre a importância da integração do Lean e Green, mesmo que esta ocorra pelo uso de alguns conceitos e ferramentas. Com o uso integrado do Lean e Green ganhos ambientais e financeiros foram destacados nestes artigos. $\mathrm{O}$ quadro 3 apresenta uma classificação do conteúdo dos artigos.

Quadro 3 - Classificação específica do conteúdo dos artigos

\begin{tabular}{|c|c|c|c|}
\hline & $\begin{array}{l}\text { Vendrametto, O., et al. } \\
(2010)\end{array}$ & $\begin{array}{l}\text { Junior J. A. S. et al. } \\
\text { (2014) }\end{array}$ & Kauer R. (2015) \\
\hline Palavras-chave & $\begin{array}{c}\text { Melhoria de } \\
\text { produtividade, } \\
\text { eliminação de resíduos, } \\
\text { Fator de Intensidade de } \\
\text { Material. }\end{array}$ & $\begin{array}{c}\text { Lean Manufacturing, } \\
\text { Green Manufacturing, } \\
\text { Reforma e Recapagem } \\
\text { de Pneus. } \\
\text { Sustentabilidade }\end{array}$ & $\begin{array}{c}\text { Laminados } \\
\text { sintéticos, Resíduos } \\
\text { de Poliuretano, } \\
\text { Produção mais } \\
\text { Limpa, Lean } \\
\text { Manufacturing. }\end{array}$ \\
\hline Objetivo & $\begin{array}{l}\text { Busca melhorar o uso } \\
\text { de embalagens de } \\
\text { madeira, papelão e } \\
\text { plástico, usando os } \\
\text { métodos Enxutos e } \\
\text { Produção mais Limpa. }\end{array}$ & $\begin{array}{l}\text { O trabalho analisa o } \\
\text { grau de interação entre } \\
\text { Lean Manufacturing e } \\
\text { Green Manufacturing e } \\
\text { busca identificar os } \\
\text { principais desperdícios. }\end{array}$ & $\begin{array}{c}\text { Diminuir a emissão } \\
\text { de resíduos } \\
\text { aplicando os } \\
\text { sistemas Lean } \\
\text { Manufacturing e } \\
\text { Cleaner Production. }\end{array}$ \\
\hline Método empregado & $\begin{array}{l}\text { Revisão da literatura e } \\
\text { estudo de caso. }\end{array}$ & $\begin{array}{l}\text { Revisão da literatura e } \\
\text { estudo de caso. }\end{array}$ & $\begin{array}{c}\text { Revisão da } \\
\text { literatura e estudo } \\
\text { de caso. }\end{array}$ \\
\hline Setor de aplicação & Setor de logística & Setor de produção & Setor de produção \\
\hline $\begin{array}{l}\text { Resultados } \\
\text { alcançados }\end{array}$ & $\begin{array}{c}\text { Ganhos financeiros, de } \\
\text { espaço e de } \\
\text { produtividade, } \\
\text { diminuição de } \\
\text { desperdícios de } \\
\text { materiais. }\end{array}$ & $\begin{array}{l}\text { Redução de energia e } \\
\text { uso de materiais, } \\
\text { reciclagem de materiais. }\end{array}$ & $\begin{array}{l}\text { Redução na } \\
\text { emissão de } \\
\text { resíduos e } \\
\text { reciclagem de } \\
\text { material. }\end{array}$ \\
\hline
\end{tabular}

Fonte: Autores (2016)

No quadro 3 são classificados os artigos. Os três artigos utilizaram métodos teóricos e empíricos de caráter exploratório e os estudos foram aplicados em setores diferentes. Os artigos apresentam resultados importantes para a produtividade e a sustentabilidade de uma organização. A palavra-chave Lean Manufacturing aparece em dois dos artigos analisados.

Com a análise dos artigos, foi possível destacar os indicadores, ferramentas e práticas usadas, organizadas no quadro 4. No artigo Produção mais limpa: um movimento crescente em empresas brasileiras (Vendrametto ET al., 2010), foram encontrados os seguintes indicadores: Ganho Ambiental (environment gain), que permitiu calcular os ganhos ambientais com a fórmula $E G=M M^{*} M I F$, na qual $M M$ é a massa de material. MIF são os fatores de intensidade de materiais, uma ferramenta 
de avaliação de material onde avalia os distúrbios ambientais associados com a extração de materiais do ambiente, divididos em: abióticos, bióticos, água e ar (Recursos consumidos por unidade de produção).

As ferramentas encontradas foram: Gerenciamento da cadeia de suprimento (mudanças no modelo de suprimento dos componentes, aumentando o número de entregas para diminuir os estoques), Kaizen, Just in Time, Produção celular, Gerenciamento total da qualidade e 3R.

As práticas apresentadas foram: reuso dos pallets que são recebidos com as entregas e retrabalho para adapta-los para serem usados nas entregas dos produtos, reciclagem; Redução no uso de materiais nas embalagens dos componentes, redução de desperdício de materiais; Redução no tempo de produção; Lotes com maior quantidade de material, para diminuir as embalagens; Fluxograma de processo da produção da empresa;

No artigo Estudo da interação entre Lean Manufacturing e Green Manufacturing em uma indústria de reforma e recapagem de pneus (Junior J. A. S. et al., 2014) foram encontrados os seguintes indicadores: Redução das emissões e Consumo de energia. Observou-se no artigo o uso destes indicadores, mas não foram apresentadas as fórmulas de cálculo.

As ferramentas encontradas foram: Gerenciamento da cadeia de suprimento, Takt time, Produção celular, 3R, Gerenciamento total da qualidade. Já as melhores práticas encontradas foram: reciclagem, redução de energia, analise de produtos não conformes, treinamento de funcionários para diminuir não conformidades.

$O$ artigo Minimização do passivo ambiental de resíduos líquidos de poliuretanos em indústria de laminados sintéticos através da aplicação sinérgica de ferramentas da Produção mais Limpa e Lean Manufacturing (Kauer R. 2015) apresentou como indicador a redução de resíduos. No artigo foram usadas as ferramentas Lean Kaizen e 3R. Também foi usado as ferramentas 5W2H e PDCA a fim de montar um plano de ação para minimizar a geração de resíduos.

Como melhores práticas foram usadas: controle dos processos produtivos, melhoria constante, reciclagem e redução de emissão de resíduos. 
Quadro 4 - Indicadores, Ferramentas e Melhores práticas encontradas nos artigos

\begin{tabular}{|c|c|c|c|c|}
\hline Artigos & & Artigo 1 & Artigo 2 & Artigo 3 \\
\hline \multirow{2}{*}{ Indicadores } & Lean & 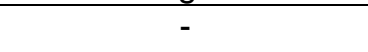 & & \\
\hline & Cleaner & $\begin{array}{c}\text { Ganho ambiental; } \\
\text { Fatores de intensidade } \\
\text { de materiais (MIF); } \\
\text { Redução de materiais. }\end{array}$ & $\begin{array}{l}\text { Redução de emissões; } \\
\text { Consumo de energia. }\end{array}$ & Redução de resíduos \\
\hline \multirow[t]{2}{*}{ Ferramentas } & Lean & $\begin{array}{c}\text { Gerenciamento da } \\
\text { cadeia de Suprimento; } \\
\text { Kaizen; } \\
\text { Just in Time; } \\
\text { Produção celular; } \\
\text { Gerenciamento total } \\
\text { da qualidade; } \\
\text { 3R. }\end{array}$ & $\begin{array}{l}\text { Gerenciamento da } \\
\text { cadeia de Suprimento; } \\
\text { Takt time; } \\
\text { Produção celular; } \\
\text { 3R; } \\
\text { Gerenciamento total } \\
\text { da qualidade. }\end{array}$ & $\begin{array}{c}\text { Kaizen } \\
3 R\end{array}$ \\
\hline & Cleaner & - & - & - \\
\hline \multirow[t]{2}{*}{$\begin{array}{l}\text { Melhores } \\
\text { práticas }\end{array}$} & Lean & $\begin{array}{c}\text { Redução no tempo de } \\
\text { produção; } \\
\text { Mudança nos lotes; } \\
\text { Fluxograma de } \\
\text { processo. }\end{array}$ & $\begin{array}{l}\text { Análise de produtos } \\
\text { não conformes; } \\
\text { Treinamento de } \\
\text { funcionários. }\end{array}$ & $\begin{array}{c}\text { Controle dos } \\
\text { processos produtivos } \\
\text { Constante melhoria }\end{array}$ \\
\hline & cleaner & $\begin{array}{l}\text { Reciclagem; } \\
\text { Redução de } \\
\text { desperdício de } \\
\text { materiais. }\end{array}$ & $\begin{array}{c}\text { Reciclagem; } \\
\text { Redução de energia. }\end{array}$ & $\begin{array}{c}\text { Reciclagem } \\
\text { Redução de emissão } \\
\text { de resíduos }\end{array}$ \\
\hline
\end{tabular}

Fonte: Autores (2016)

Vale ressaltar que dos três artigos, dois apresentaram lacunas para possíveis trabalhos futuros, o que indica que há muito a ser estudado e pesquisado sobre a união de Lean Manufacturing e Cleaner Production.

\subsection{Proposta para integração dos sistemas}

O artigo Cleaner production: a growing movement in brazilian companies (Vendrametto et al., 2010), apresenta a integração de Lean e Cleaner Production, com a análise de três estudos de caso. A integração dos princípios Lean e Cleaner Production acontece com a diminuição das embalagens nos materiais necessários na produção. Isso diminui o uso de matéria prima para as embalagens, diminuindo o desperdício e ajuda a diminuir o tempo necessário para embalar e desembalar os pacotes. Nos estudos de casos foram comprovados a diminuição de tempo, de materiais das embalagens como plásticos e madeira e um ganho financeiro para as empresas. 
O outro artigo que aborda a relação entre Lean e Cleaner Production é o Estudo da interação entre lean manufacturing e green manufacturing em uma indústria de reforma e recapagem de pneus (Silva Junior J. A. et al., 2014). Houve a integração de Lean e Green no processo de vulcanização, no qual foi realizada uma melhoria para reutilizar o vapor do processo, o que reduziu o tempo necessário para aquecer a água e a diminuição da energia necessária para o processo. A empresa buscou melhorar a qualificação dos profissionais para que houvesse menos produtos não conformes, o que desperdiçaria materiais e tempo. Os resultados obtidos foram em relação à diminuição dos impactos ambientais e dos custos.

No artigo Minimização do passivo ambiental de resíduos líquidos de poliuretanos em indústria de laminados sintéticos através da aplicação sinérgica de ferramentas da produção mais limpa e lean manufacturing (Kauer R., 2015) também foi observado a integração dos sistemas de produção. Foi proposto um plano de ação para controlar e diminuir a emissão de resíduos na produção a partir de ferramentas como PDCA, Kaizen e 3R. Foram obtidos bons resultados em relação a diminuição da emissão e reciclagem dos resíduos.

Os demais artigos encontrados não abordam a integração de Lean Manufacturing e Cleaner Production. Com as comparações entre os artigos foi percebido alguns indicadores, práticas e ferramentas que facilitam a integração dos sistemas de produção Lean Manufacturing e Cleaner Production, organizados na figura 3.

Empresas que possuem os indicadores de diminuição de energia e materiais apresentam ganhos significativos em redução de custos e diminuem os impactos ambientais, pois consomem menos e geram menos resíduos.

A ferramenta de gestão da cadeia de suprimentos apresentou em ambos os artigos melhorias quanto ao tempo e eficiência em questões de estoque, com a diminuição de uso de embalagens, diminuindo a quantidade de lixo gerado, menos tempo envolvido nos suprimentos que geraram ganhos de produtividade, entregas mais frequentes ajudaram a diminuir o estoque.

Em ambos os artigos, a reciclagem foi importante para a integração pois diminuiu a quantidade de material descartado que passou a ser reciclado, diminuindo a quantidade de resíduos descartados para o ambiente e as empresas conseguiram diminuir gastos, usando os materiais que seriam descartados para embalar peças e 
itens, em um caso específico os resíduos de pneus que eram descartados, passaram a ser vendidos para outra empresa.

Figura 3 - Integração dos indicadores, melhores práticas e ferramentas dos Sistemas Lean Manufacturing e Cleaner Production

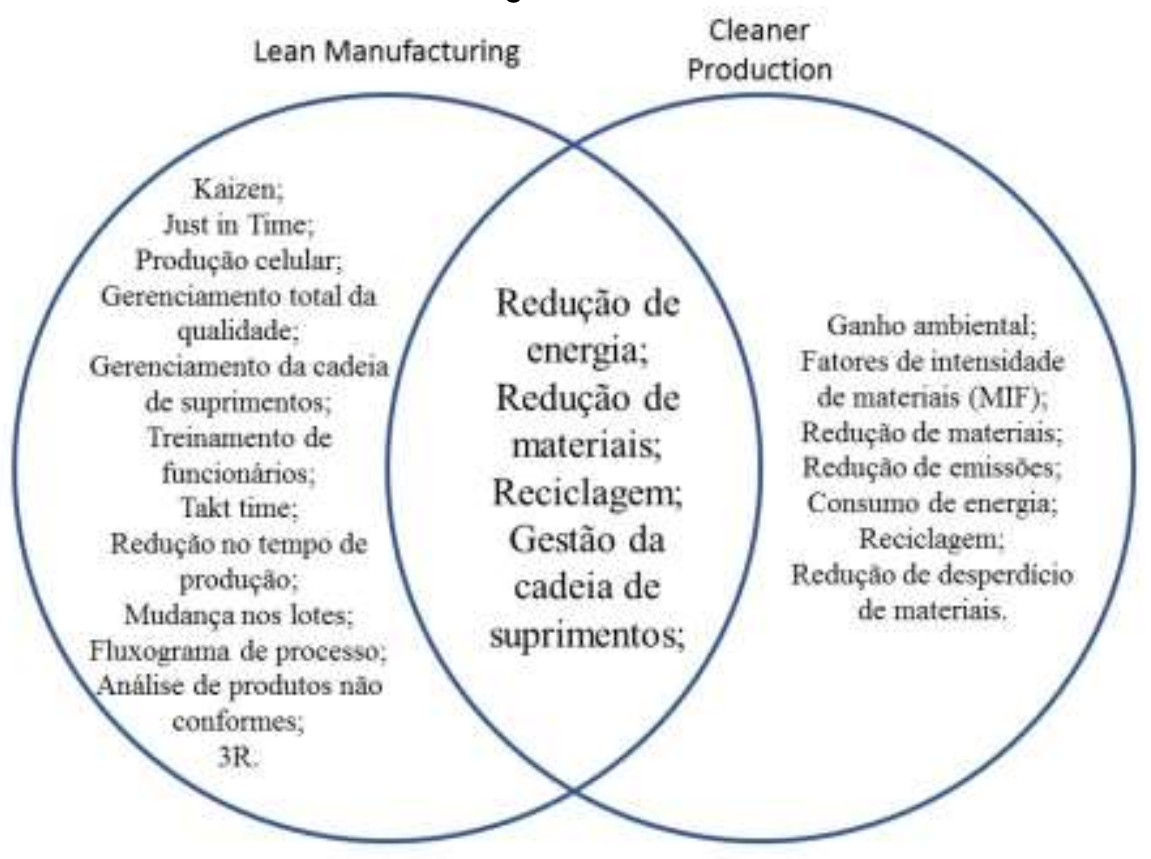

Fonte: Autores (2016)

\section{CONCLUSÃO}

O sistema de produção Lean Manufacturing, que foi criado após a segunda guerra mundial e ficou conhecido como Sistema Toyota de Produção (Ohno, 1988), já é amplamente estudado e apresentou muitos resultados com a pesquisa. O sistema de produção Cleaner Production surgiu em 1989 e está em crescimento no cenário nacional e já ganham espaço no ENEGEP e periódicos ligados à ABEPRO. Porém, com o uso da cientometria foi possível perceber uma grande lacuna em relação ao uso dos sistemas de produção em conjunto. Apenas oito artigos foram encontrados na pesquisa que relacionam Lean Manufarturing e Cleaner Production. Destes, após a análise qualitativa, apenas dois abordam de fato a integração dos sistemas produtivos.

É preciso avançar nas pesquisas sobre Lean Manufacturing e Cleaner Production para que o conhecimento dos métodos seja difundido no país e permita 
um crescimento da produção mais limpa e sem desperdícios, com grandes ganhos para o meio ambiente e para as próprias empresas.

Para trabalhos futuros sugere-se a realização de uma nova análise cientométrica em bases de dados internacionais, com o uso de mais palavras-chave e, a aplicação em uma empresa dos dois sistemas de produção para avaliar os ganhos e as diminuições de custos e resíduos gerados.

\section{REFERÊNCIAS}

ABEPRO. Associação Brasileira de Engenharia de Produção. Informações sobre a ABEPRO. Disponível em: http://www.abepro.org.br/interna.asp? $\mathrm{p}=332 \& \mathrm{~m}=332 \& s s=1 \& \mathrm{c}=359$. Acesso em: 30 ago. 2016.

BAAS, Leo W. Cleaner production: beyond projects. Journal of Cleaner Production, v. 3, n. 1, p. 55-59, 1995. https://doi.org/10.1016/0959-6526(95)00042-D

BOMFÁ, Cláudia Regina Ziliotto; CASTRO, João Ernesto E. Desenvolvimento de revistas científicas em mídia digital: o caso da Revista Produção Online. Ciência da Informação, Brasília, v. 33, n. 2, p. 39-48, 2004. http://dx.doi.org/10.1590/S0100-19652004000200004

BALAN, M.; KLOTZ, R.; SANTOS, J. A; NEVES, L. A. P.; CHIDAMBARAM, C. Uma proposta de ferramentas computacionais de gestão da produção para indústria moveleira. In: ENCONTRO NACIONAL DE ENGENHARIA DE PRODUÇÃO, 29., 2009. Anais... Salvador. Rio de Janeiro: ABEPRO, 2009.

BITTENCOURT, Larissa Arianne Fantin; ADE, Paula. Análise cienciométrica de produção científica em unidades de conservação federais do Brasil. Enciclopédia Biosfera, v. 8, n. 14, p. 2044-2054, 2012.

DOMINGO, Rosario; AGUADO, Sergio. Overall Environmental Equipment Effectiveness as a Metric of a Lean and Green Manufacturing System. Sustainability, v. 7, n. 7, p. 9031-9047, 2015. http://dx.doi.org/10.3390/su7079031

DUMKE, DENISE; CALÁBRIA, MEDEIROS FELIPE ALVES. Aplicação da produção mais limpa em uma empresa como ferramenta de melhoria contínua. Produção, v. 17, n. 1, p. 109-128, Jan./Abr. 20072007. http://dx.doi.org/10.1590/S0103-65132007000100008

DUNN, Russell F.; BUSH, Greg E. Using process integration technology for CLEANER production. Journal of cleaner production, v. 9, n. 1, p. 1-23, 2001.

https://doi.org/10.1016/S0959-6526(00)00021-4

ENEGEP. Encontro Nacional de Engenharia de Produção. Informações sobre o ENEGEP. Disponível em:

https://www.abepro.org.br/enegep/2017/interna.asp?m=1397\&c=1418\&p=1342. Acesso em: 05 jan. 2017.

FRAZZON, Lorenzo Sanfelice; INOMATA, Danielly Oliveira; OLIVEIRA, Karla Fabrícia de; FORCELLINI, Fernando Antônio. O processo de desenvolvimento de um serviço inovador 
com base em um modelo de referência. Revista Produção Online, v. 15, n. 2, p. 622-645, 2015. http://dx.doi.org/10.14488/1676-1901.v15i2.1933

FURLAN, Andrea; VINELLI, Andrea; DAL PONT, Giorgia. Complementarity and lean manufacturing bundles: an empirical analysis. International Journal of Operations \& Production Management, v. 31, n. 8, p. 835-850, 2011. https://doi.org/10.1108/01443571111153067

GALEAZZO, Ambra; FURLAN, Andrea; VINELLI, Andrea. Lean and green in action: interdependencies and performance of pollution prevention projects. Journal of Cleaner Production, v. 85, p. 191-200, 2014. https://doi.org/10.1016/.j.jclepro.2013.10.015

GETZNER, Michael. The quantitative and qualitative impacts of clean technologies on employment. Journal of Cleaner Production, v. 10, n. 4, p. 305-319, 2002.

https://doi.org/10.1016/S0959-6526(01)00042-7

GHINATO, Paulo. Sistema Toyota de Produção: mais do que simplesmente just-in-time. Production, v. 5, n. 2, p. 169-189, 1995. http://dx.doi.org/10.1590/S0103-65131995000200004

GLAVIČ, Peter; LUKMAN, Rebeka. Review of sustainability terms and their definitions. Journal of cleaner production, v. 15, n. 18, p. 1875-1885, 2007.

https://doi.org/10.1016/j.jclepro.2006.12.006

HÖCKERDAL, Karin. Enhancing the process of environmental improvement in manufacturing industry. (2012) Disponível em: http://www.divaportal.org/smash/record.jsf?pid=diva2\%3A524035\&dswid=-6020 . Acesso em: 05 jan. 2017.

HUTCHINS, David. Just in time. Gower Publishing, Ltd., 1999.

KAUER, R. Minimização do passivo ambiental de resíduos líquidos de poliuretanos em indústria de laminados sintéticos através da aplicação sinérgica de ferramentas da produção mais limpa e lean manufacturing In: ENCONTRO NACIONAL DE ENGENHARIA DE PRODUÇÃO, 35., 2015. Anais... Fortaleza. Rio de Janeiro: ABEPRO, 2015.

MAGNAGO, Patrícia Flores; DE AGUIAR, João Pedro Ornaghi; DE PAULA, Istefani Carisio. Sustentabilidade em desenvolvimento de produtos: uma proposta para a classificação de abordagens. Revista Produção Online, v. 12, n. 2, p. 352-376, 2012.

http://dx.doi.org/10.14488/1676-1901.v12i2.796

MARIZ, Renato Nunes; PICCHI, Flávio Agusto. Aplicação de célula de produção no serviço de execução de fachada: um estudo de caso na construção civil. Revista Produção Online, v. 14, n. 2, p. 703-719, 2014. http://dx.doi.org/10.14488/1676-1901.v14i2.1499

MINGERS, John; LEYDESDORFF, Loet. A review of theory and practice in scientometrics. European Journal of Operational Research, v. 246, n. 1, p. 1-19, 2015.

https://doi.org/10.1016/i.ejor.2015.04.002

ROTHER, Mike; SHOOK, John. Learning to see: value stream mapping to add value and eliminate muda. Lean Enterprise Institute, 2003.

SELLITTO, Miguel Afonso; BORCHARDT, Miriam; PEREIRA, Giancarlo Medeiros; Pacheco, Diego Augusto de Jesus. Gestão de cadeias de suprimentos verdes: quadro de trabalho.

Revista Produção Online, v. 13, n. 1, p. 351-374, 2013.

http://dx.doi.org/10.14488/1676-1901.v13i1.1181 
SILVA, José Aparecido da; BIANCHI, Maria de Lourdes Pires. Scientometrics: the measurement of science. Paidéia (Ribeirão Preto), v. 11, n. 21, p. 5-10, 2001. http://dx.doi.org/10.1590/S0103-863X2001000200002

SILVA FILHO, Júlio Cezar Gomes; SICSÚ, Abraham Benzaquem. Produção mais Limpa: uma ferramenta da Gestão Ambiental aplicada às empresas nacionais. In: ENCONTRO NACIONAL DE ENGENHARIA DE PRODUÇÃO, 23., 2003. Anais... Ouro Preto, Minas Gerais, Rio de Janeiro: ABEPRO, 2003.

SILVA JUNIOR, J. A.; TAKEMOTO, L.; PEREIRA, M. A. C. Estudo da interação entre lean manufacturing e green manufacturing em uma indústria de reforma e recapagem de pneus. In: ENCONTRO NACIONAL DE ENGENHARIA DE PRODUÇÃO, 34., 2014. Anais... Curitiba. Rio de Janeiro: ABEPRO, 2014.

SPINAK, Ernesto. Indicadores cienciométricos. Ci. Inf., v. 27, n. 2, p. 141-148, maio/ago. 1998. http://dx.doi.org/10.1590/S0100-19651998000200006

SEVERO, Eliana Andréa et al. Cleaner production, environmental sustainability and organizational performance: an empirical study in the Brazilian Metal-Mechanic industry. Journal of Cleaner Production, v. 96, p. 118-125, 2015.

https://doi.org/10.1016/j.jclepro.2014.06.027

SUGIMORI, Y; KUSONOKI, K.; CHO, F.; UCHIKAWA, S. Toyota production system and kanban system materialization of just-in-time and respect-for-human system. The

International Journal of Production Research, v. 15, n. 6, p. 553-564, 1977. http://dx.doi.org/10.1080/00207547708943149

VENDRAMETTO, Oduvaldo; PALMERI, Nivaldo; NETO, Geraldo Cardoso; PERRETTI, Osvaldo D'Angelo. Cleaner production: a growing movement in Brazilian companies.

Revista Produção Online, v. 10, n. 1, 2010. http://dx.doi.org/10.14488/1676-1901.v10i1.240

VERRIER, Brunilde; ROSE, Bertrand; CAILLAUD, Emmanuel; REMITA, Hakim. Combining organizational performance with sustainable development issues: the Lean and Green project benchmarking repository. Journal of Cleaner Production, v. 85, p. 83-93, 2014. https://doi.org/10.1016/j.jclepro.2013.12.023

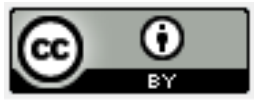

Artigo recebido em 07/03/2017 e aceito para publicação em 11/08/2017 DOI: http://dx.doi.org/10.14488/1676-1901.v18i1.2796 